\title{
O mercado internacional de produtos lácteos: os efeitos do acordo Mercosul-UE sobre o Brasil
}

\author{
Augusto Mussi Alvim* \\ Silvana Longo Moraes ${ }^{* *}$
}

RESUMO - Este artigo analisa o mercado internacional de produtos lácteos e os efeitos do acordo Mercosul-UE sobre o setor de lácteos no Brasil. Para atingir este objetivo são apresentados os principais países produtores e consumidores de lácteos no mundo e discutidos os ganhos e as perdas potenciais no caso do Mercosul-UE. É utilizado um modelo de equilíbrio parcial formulado como um Problema de Complementaridade Mista que permite avaliar mudanças em termos de produção, consumo e comércio considerando diferentes cenários alternativos. Este modelo considera multirregiões e multiprodutos, o que permite analisar o impacto de políticas de livre comércio para regiões selecionadas e diversos produtos lácteos.

Palavras-chave: Produtos lácteos. Mercosul-UE. Mercado brasileiro.

\section{INTRODUÇÃO}

O mercado de lácteos no Brasil e no mundo mudou expressivamente nas últimas duas décadas em função da ampliação do fluxo comercial e financeiro decorrente do processo de liberalização dos mercados. O maior fluxo comercial promove um ambiente de maior concorrência, estimula um maior fluxo de investimentos e contribui para manter a estabilidade econômica. Já os investimentos diretos recebidos pelo Brasil, por exemplo, têm contribuído para estimular o crescimento e as exportações brasileiras através de uma maior especialização nas atividades com a obtenção de ganhos de escala e a adoção de novas tecnologias.

Apesar disto, o comércio internacional de produtos agrícolas tem se tornado cada vez mais complexo, com uma maior diversidade de barreiras tarifárias, não-tarifárias e subsídios concedidos pelos países desenvolvidos. Estes mecanismos, por sua vez, tornaram-se mais complicados devido à criação de novos produtos e ao fortalecimento de grupos de pressão nestes países, os quais passaram a cobrar mais pelo "protecionismo seletivo".

\footnotetext{
* Pós-Doutor pela Massey University, Nova Zelândia. Doutor em Economia pela UFRGS. Professor do Departamento de Ciências Econômicas e do Programa de Pós-Graduação em Economia (PPGE) da PUCRS. Endereço eletrônico: augusto.alvim@pucrs.br.

** Aluna de graduação da PUCRS. Bolsista da FAPERGS no Núcleo de Pesquisas em Economia (NEPEPPGE).
} 
Um exemplo desta problemática pode ser observado no setor de lácteos onde é possível identificar um número expressivo de tarifas ad valorem e quotas tarifárias que podem variar conforme o tipo e a especificação do produto, a região de origem e os acordos comerciais pré-existentes.

Este setor tem crescido significativamente em função do aumento da renda nos países emergentes, especialmente nos países asiáticos. Esta expansão na demanda associada a melhores preços para o leite e seus derivados tem contribuído para fortalecer o comércio de lácteos no mercado internacional. Todavia, este crescimento observado na produção de lácteos pode ser ampliado com uma nova onda de acordos comerciais.

Neste sentido, acordos regionais a exemplo do Mercosul-UE poderiam intensificar o fluxo comercial principalmente entre o Brasil e os países da UE. Com base nisto, neste estudo são identificados os principais atores neste mercado e os possíveis ganhos e perdas do acordo Mercosul-UE para os países envolvidos. Para simular estes cenários alternativos foi utilizado de um modelo de alocação espacial e vertical para identificar os efeitos deste acordo regional sobre a produção, consumo e comércio nos países envolvidos.

\section{O MERCADO INTERNACIONAL DE LÁCTEOS}

Nesta seção inicialmente são apresentados os principais produtores e exportadores líquidos de produtos lácteos, a fim de identificar os países e regiões que atuam neste mercado. A segunda parte consiste na análise mais detalhada do setor de lácteos nos países do Mercosul e da UE, avaliando comparativamente a produção e o consumo de leite e derivados nestas regiões.

A produção de lácteos no mundo é espacialmente concentrada. Sendo os países da UE, os EUA e o Canadá produtores de quase 50\% do total mundial (Figura 1). Para estes países existe um conjunto comum de características importantes que explicam a maior relevância desta atividade nestas regiões. Entre elas destaca-se a elevada renda per capita destes países, o desenvolvimento tecnológico na produção de leite e derivados e as políticas protecionistas praticadas por estes países (quotas-tarifárias e subsídios).

Tradicionalmente os países da UE, os EUA e o Canadá protegem seus produtores através de mecanismos como barreiras tarifárias (tarifas e quotas-tarifárias) e subsídios. Os primeiros têm por objetivo reduzir a concorrência com os produtos domésticos, tornando viável manter os preços internos mais elevados do que os do mercado internacional. Já os 
subsídios têm por objetivo elevar o nível de renda dos produtores rurais e viabilizar a exportação dos excedentes ao mercado internacional.

Como reflexo disto a UE é a maior produtora e a segunda maior região exportadora de lácteos, exportando em termos líquidos 7.379 toneladas de equivalente leite, média para 2004-06. O EUA também é um exportador líquido de leite, embora com uma pequena participação (Figura 2). Enquanto o Canadá é um importador líquido de lácteos, ainda que com um volume reduzido. Conforme comentado anteriormente, a estratégia de proteção da produção de lácteos torna o desempenho destes países mais competitivo frente aos demais países.

FIGURA 1 - PRODUÇÃO DE LEITE NAS PRINCIPAIS REGIÕES PRODUTORAS (\%) - 2004-2006

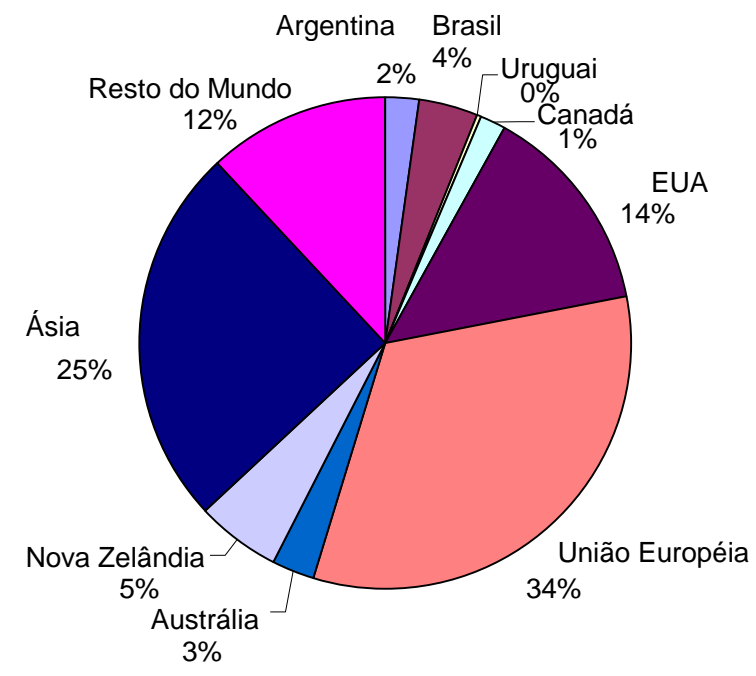

FONTE: OCDE, 2008.

Já países como Austrália e Nova Zelândia representam uma parcela pequena da produção mundial (8\%), contudo são os maiores exportadores de leite e derivados. Apesar de não proteger os seus mercados e tampouco subsidiar a produção, estes países têm acesso facilitado ao mercado europeu e americano, o que propicia um maior intercâmbio financeiro, tecnológico e comercial entre as regiões.

A Ásia possui uma importante produção no mercado internacional, representando $25 \%$ do total no período analisado (Figura 1). Devido ao alto consumo desta região, a produção não é suficiente para abastecer este mercado, sendo necessário importar de outras regiões. Neste sentido, conforme apresentado na Figura 2, as importações líquidas médias para este período foram de 18.832 toneladas de equivalente leite. Atualmente esta é maior região importadora, apresentando volumes crescentes de produtos importados decorrentes do 
aumento da renda. Esta dinâmica de crescimento esta sendo propiciada principalmente por países como a China e a Índia.

FIGURA 2 - EXPORTAÇÕES LÍQUIDAS DE PRODUTOS LÁCTEOS (TONELADAS)- 2004-2006

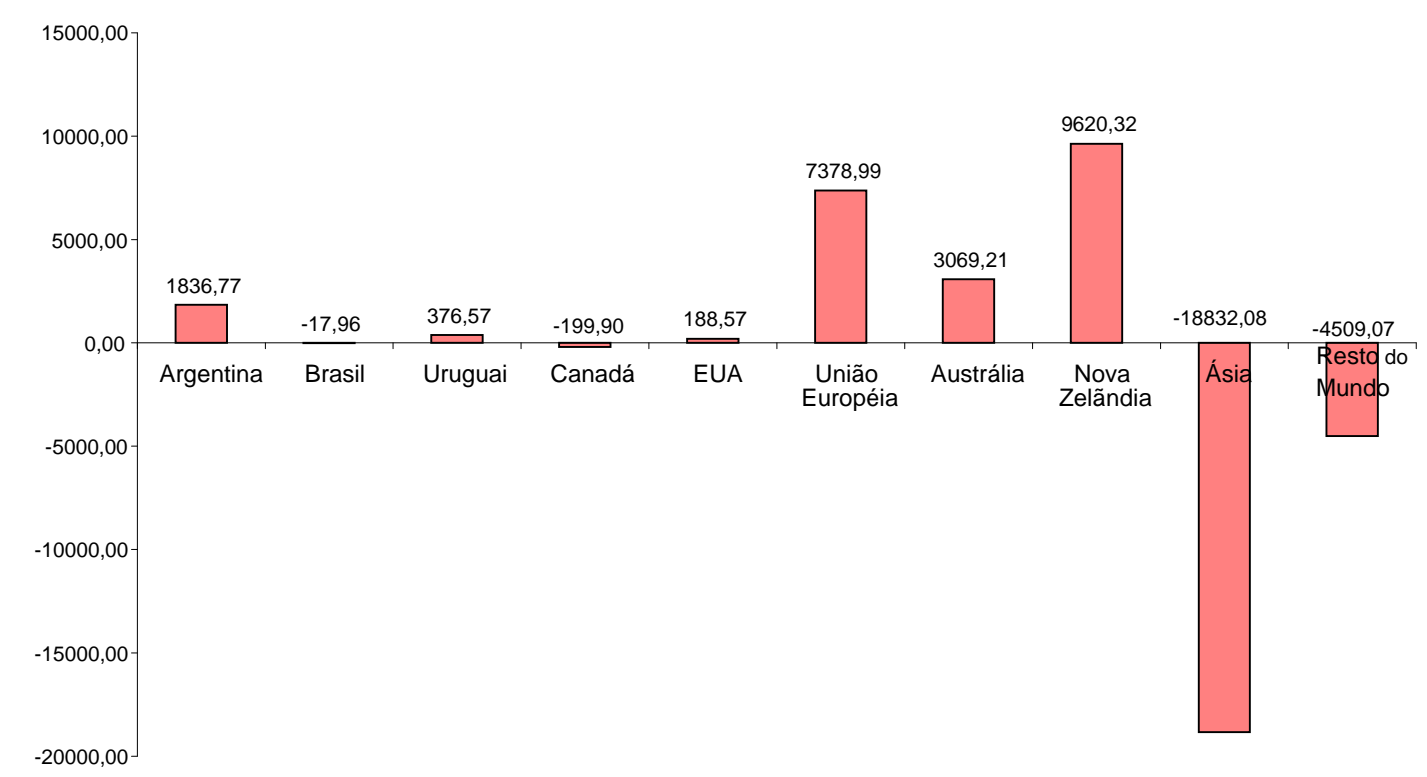

FONTE: OCDE, 2008.

Os países do Mercosul apresentam por sua vez uma pequena participação na produção mundial de lácteos. Conjuntamente eles representam $6 \%$ do total mundial, com um volume de exportações líquidas de 2.195 toneladas, significativamente menor do que o de países como a Austrália e a Nova Zelândia.

A maior parte da produção de leite e derivados dos países do Mercosul destina-se a atender a demanda dos países que compõem este bloco. Por sua vez, a ausência de suporte governamental e a concorrência com produtos importados subsidiados limitam a capacidade competitiva destes países frente a tradicionais países exportadores.

Nos países do Mercosul existem apenas as barreiras tarifárias (tarifas ad valorem) e não existe a prática de subsídios. Para o setor de lácteos a tarifa média aplicada é de 14\%, contudo esta pode aumentar dependendo do produto derivado de leite.

Desta forma, é importante avaliar de forma mais detalhada o perfil da produção de leite e derivados nos países do Mercosul e da UE a fim de avaliar os segmentos potenciais de incremento das importações para estes mercados e os possíveis benefícios e perdas decorrentes de acordos regionais entre estes blocos.

$\mathrm{Na}$ Figuras 3 e 4 são apresentadas a produção e consumo de leite e derivados para os países do Mercosul e para a UE. Além de reafirmar as diferenças entre quantidade produzida 
e consumida entre os dois blocos, é possível identificar que o padrão de consumo de lácteos nos países da UE se dá preferencialmente na forma de leite fluido (34.804 t.), queijo (8.154 t.) e manteiga (2.012 t.).

FIGURA 3 - PRODUÇÃO E CONSUMO DE LEITE FLUÍDO EM PAÍSES SELECIONADOS (TONELADAS) - 2004-2006

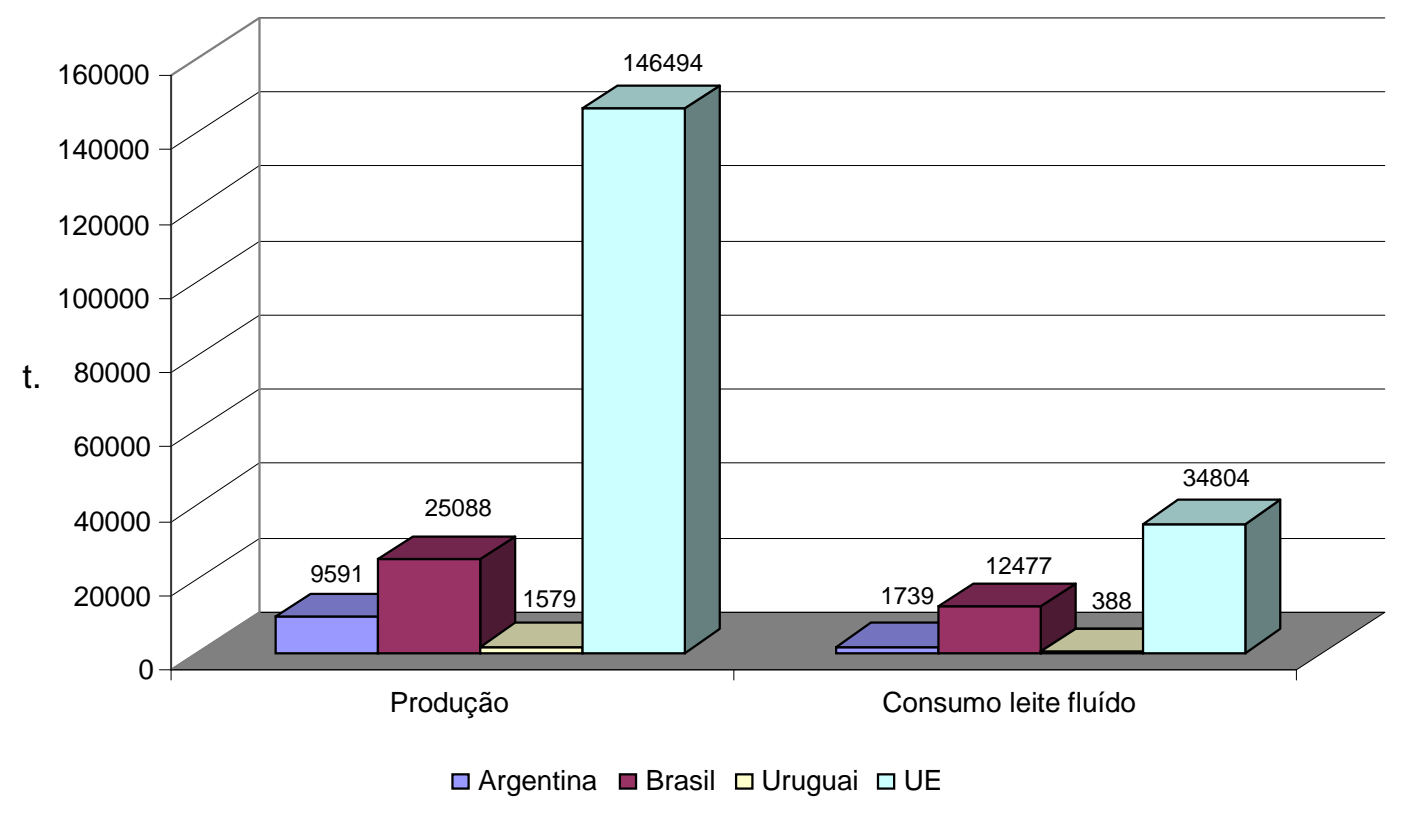

FONTE: OCDE, 2008

Por outro lado, para os países do Mercosul, os principais produtos consumidos são: o leite fluido (14.604 t.), o queijo (873 t.) e o leite em pó integral (483 t.) para o período analisado. Devido a aspectos tecnológicos e as características do mercado consumidor, os produtos em que os países do Mercosul apresentam uma maior competitividade nas exportações são leite em pó integral e queijos. Estes produtos são exportados pela Argentina e pelo Uruguai para diversos mercados incluindo o mercado brasileiro.

$\mathrm{Na}$ próxima seção são apresentados os resultados quanto a simulação da formação de uma área de livre comércio entre os países do Mercosul e a UE, contudo mantendo os subsídios europeus. 
FIGURA 4 - CONSUMO DE LEITE EM PÓ INTEGRAL E DESNATADO, MANTEIGA E QUEIJO (TONELADAS) - 2004-2006

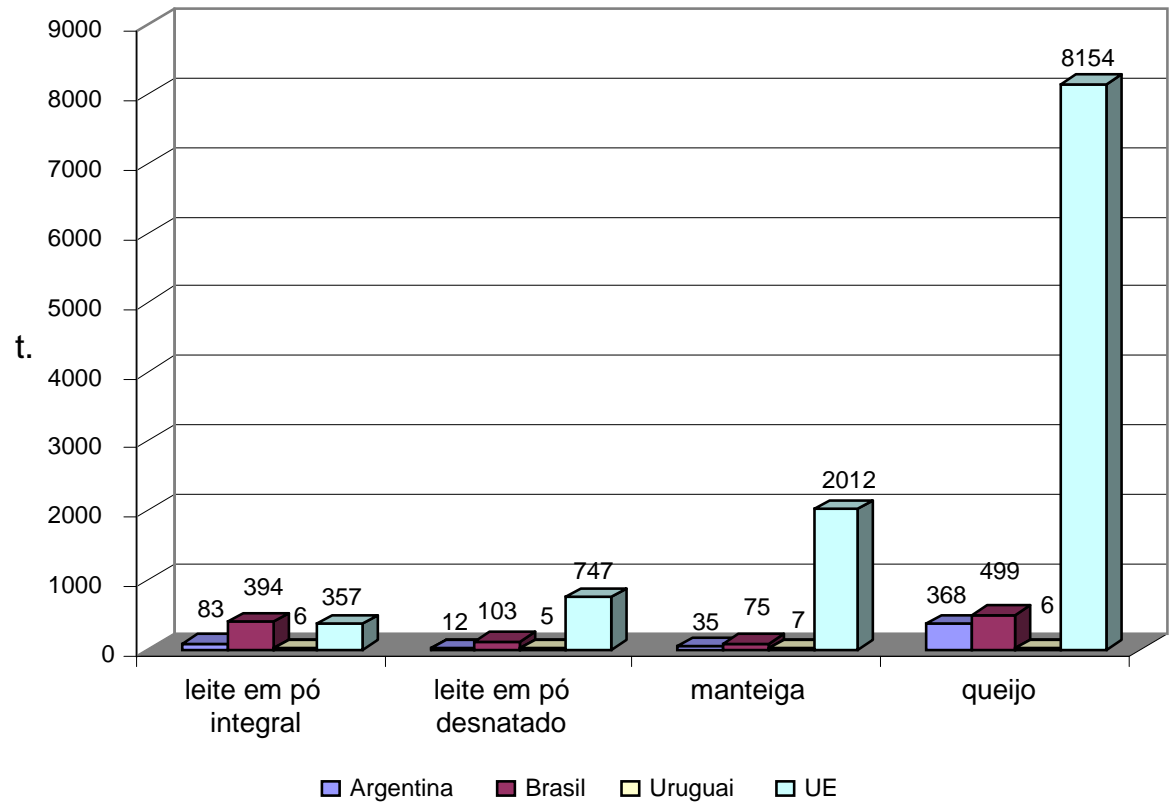

FONTE: OCDE, 2008

\section{CENÁRIOS PARA O SETOR DE LÁCTEOS NOS PAÍSES DO MERCOSUL-UE}

O objetivo de avaliar cenários alternativos é identificar as possíveis mudanças no mercado de lácteos mediante a implementação de políticas comerciais. Nesta parte são avaliadas as principais mudanças em termos de produção e consumo em vista das mudanças nas barreiras tarifárias em relação ao cenário-base (média 2004-2006). Para isto, utiliza-se de um modelo de alocação espacial e vertical com o propósito de avaliar os efeitos sobre os produtos derivados do leite, conforme proposto por Thore (1992), Waquil (1995, 2000), Rutheford (1995), Bishop, Nicholson e Pratt (2001), Alvim (2003), Nicholson e Bishop (2004), Alvim e Waquil (2004, 2005) e Alvim (2008).

Neste estudo é simulado o acordo de livre comércio entre os países da UE e do Mercosul e, portanto, as variações na produção e no consumo de lácteos ocorrem com maior intensidade nos países da UE e do Mercosul, participantes do bloco. Existem também mudanças na produção, no consumo e nas exportações dos países da Oceania que tem suas exportações afetadas negativamente pelo acordo, contudo estes aspectos não serão discutidos neste artigo.

Apesar de apenas as barreiras tarifárias terem sido eliminadas, o consumo de leite e derivados teve uma redução significativa nos três países do Mercosul, chegando a reduzir o 
consumo de leite em pó (integral e desnatado) no Uruguai em 19\%, no Brasil em 13\% e na Argentina em $6 \%$. Houve também um decréscimo no consumo de queijo e manteiga, os quais diminuíram no Uruguai, Brasil e na Argentina, em média, 2\% e 5\%, respectivamente (Figura $5)$.

A redução no consumo veio acompanhada de um aumento na produção de leite e nas exportações de lácteos por parte dos países do Mercosul devido aos maiores preços nos países do Mercosul neste cenário alternativo. A exemplo disto, a produção de leite neste cenário aumentou em 6\% no Uruguai, 4\% na Argentina e 2\% no Brasil (figura 5).

FIGURA 5 - VARIAÇÃO PERCENTUAL NA PRODUÇAO E NO CONSUMO DE LEITE E DERIVADOS PARA O CENÁRIO ALTERNATIVO MERCOSUL - UE

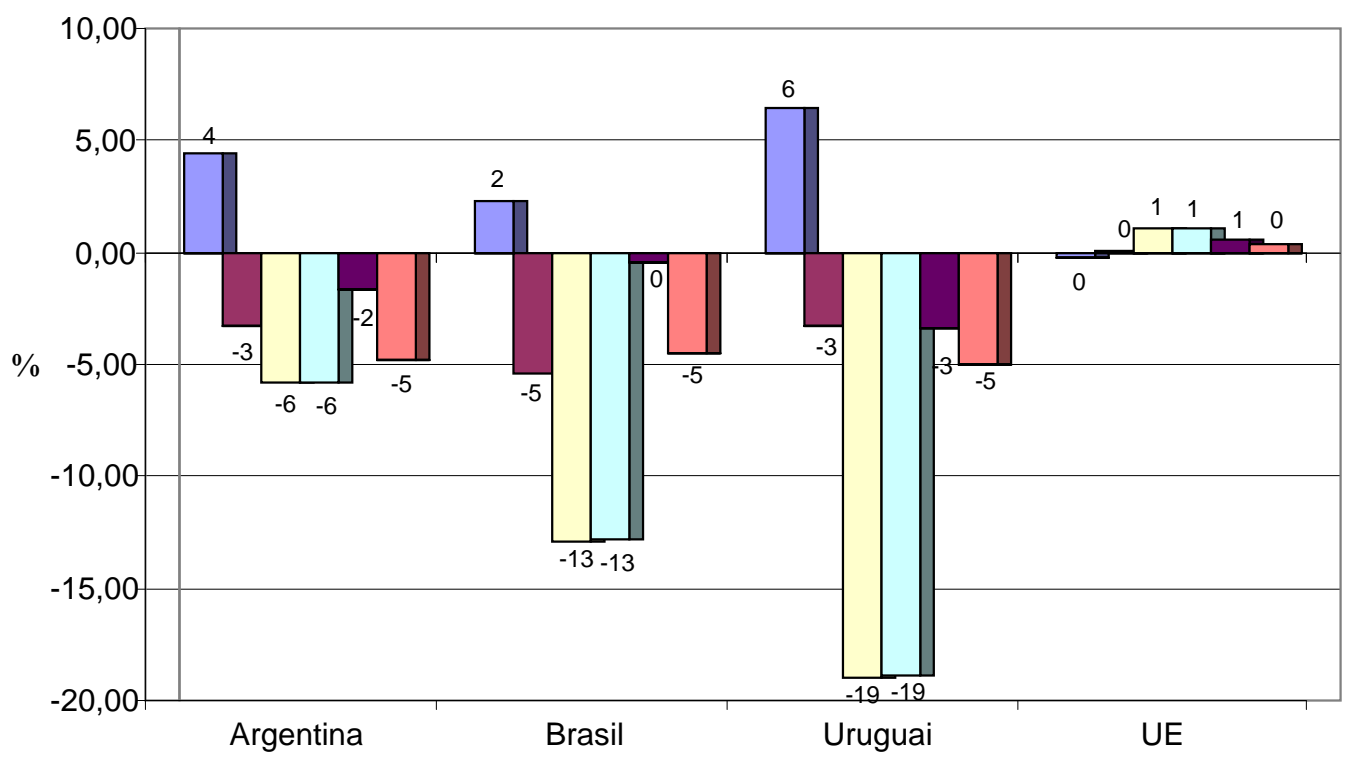

$\square$ Produção $\square$ Leite $\square$ L. pó integral $\square$ L. pó desnatado $\square$ Manteiga $\square$ Queijo

FONTE: Resultados de pesquisa.

Por outro lado, a redução na produção de leite na UE é pequena $(0,27 \%)$, assim como no consumo de leite e derivados onde o consumo de leite em pó (integral e desnatado) e de manteiga aumentou em cerca de 1\%. Isto mostra que os países da UE têm pouco a perder com um acordo regional onde são negociadas apenas a eliminação de barreiras tarifárias, mantendo os subsídios a produção. Neste cenário é possível compatibilizar ganhos para os produtores de leite dos países do Mercosul com reduzidas perdas para os produtores dos países da UE.

$\mathrm{Na}$ próxima seção são apresentadas as principais conclusões do estudo, onde são destacados os principais resultados e contribuições do estudo. 


\section{CONCLUSÕES}

Os resultados do estudo mostram que apesar dos países do Mercosul terem uma reduzida participação no mercado internacional em termos de produção e exportação existe potencial de crescimento para este segmento a partir da implementação de novos acordos regionais, a exemplo do Mercosul-UE.

Para o cenário onde são eliminadas as barreiras tarifárias, o Brasil apesar de não se tornar um exportador líquido de lácteos, sinaliza com a possibilidade dos produtores brasileiros serem beneficiados pelo fato das exportações argentinas e uruguaias serem redirecionadas para os países da UE. Este redirecionamento do fluxo comercial torna possível reduzir o excesso de oferta nos países do Cone Sul, tornando mais rentável a atividade nesta região.

Por outro lado, este acordo cria um desvio de comércio tornando as exportações dos países da Oceania menos competitivas. O que por sua vez determina à Austrália e à Nova Zelândia, tradicionais exportadores de lácteos à UE, uma redução do fluxo comercial ao mercado europeu em função da preferência concedida aos países do Mercosul.

Por fim, o estudo permite identificar a participação do setor lácteo no Brasil e nos demais países do Mercosul no cenário internacional a partir de uma análise mais detalhada sobre a demanda por leite e derivados nos países do Mercosul e da UE. Os resultados também apontam que os acordos de caráter regional que tenham reduções tarifárias permitem melhorar as condições de mercado para os produtores brasileiros. Em outras palavras, acordos regionais a exemplo do Mercosul-UE, mesmo quando mantidos os subsídios resultam em maiores benefícios para os produtores brasileiros. 


\section{REFERÊNCIAS}

ALVIM, A. M. Os Impactos dos Novos Acordos de Livre Comércio sobre o Mercado de Arroz no Brasil: um modelo de alocação espacial e temporal. Tese de Doutorado em Economia - PPGE, Universidade Federal do Rio Grande do Sul, Porto Alegre, 2003.

ALVIM, A. M. As Conseqüências dos Acordos de Livre Comércio sobre o Setor de Lácteos no Brasil, Porto Alegre, 2008. Discussão.

ALVIM, A. M. e WAQUIL, P. D. O problema de complementaridade mista: um modelo de alocação espacial aplicado ao setor agrícola. In: Santos, M. L. e Vieira, W. C. Métodos quantitativos em economia. Viçosa: UFV, 2004. p.161-190.

ALVIM, A. M. e WAQUIL, P. D. O acordo entre o Mercosul e a União Européia: efeitos sobre os mercados de grãos. In: Congresso Brasileiro de Economia e Sociologia Rural, 43., 2005. Anais ... Ribeirão Preto, SP: SOBER, 2005.

BISHOP, P.M; NICHOLSON, C.F; PRATT, J.E. Tariff-Rate Quotas: difficult to model or plain simple. In: NZIER, 2001. Paper presented at the annual conference of the New Zealand Agricultural and Resource Economics Society. Disponível em: http://www.nzier.co.nz.

EMBRAPA Gado de Leite. Índice para conversão de produtos lácteos em equivalente leite de origem. 2007. Disponível em: http://www.cnpgl.embrapa.br.

FONTERRA Co-operative Group. Milk Composition. 2007. Disponível em: www.fonterra.com.

OECD/FAO (Organisation for Economic Co-operation and Development - Food and Agriculture Organization of United Nations). The agricultural outlook database. Disponível em: http://www.oecd.org. 2007.

NICHOLSON, C. F; BISHOP, P. M. US Dairy Product Trade: Modeling Approaches and the Impact of New Product Formulations. Final Report for NRI Grant \# 200135400-10249, March 2004.w

RUTHEFORD, T.F. Extension of GAMS for complementarity problems arising in applied economic analysis. Journal of Economics Dynamics \& Control. n.19, p.1299-1324, 1995.

THORE, S. Economic logistics: the optimization of spatial and sectoral resource, production and distribution systems. New York: Westport: London: Quorum Books, 1992.

USDA-ERS (United State Department of Agriculture - Economic Research Service).

Commodity and Food Elasticities. 2007. Disponível em:

http://www.ers.usda.gov/Data/Elasticities/query.aspx.

USDA-NAL (United State Departament of Agriculture - Nutrient Data Laboratory). USDA

Food Composition Data, 2007. Disponível em: http://www.nal.usda.gov.

WAQUIL, P.D. Primal-dual spatial equilibrium model with intermediate products: application to the agricultural sector in the MERCOSUR. (Ph.D. Dissertation) University of Wisconsin - Madison, 1995.

WAQUIL, P. D. Equilíbrio espacial: modelagem e aplicação ao setor de grãos em três cenários de integração regional. In: MONTOYA, A. e PARRÉ, J. L. (eds). O Agronegócio brasileiro no final do século XX. Passo Fundo: UPF, v. 2, 2000. 
